Recebido em: 16 de agosto de 2017

Aprovado em: 01 de novembro de 2017

Sistema de Avaliação: Double Blind Review

RPR |a. 15| n. 1 |p. 105-120|jan./jun. 2018

DOI: https://doi.org/10.25112/rpr.v1i0.1356

\title{
FÉ, COMIDA E CULTURA: A FESTA DE NOSSA SENHORA do ROSÁRIO - BENTO GONÇALUES/RS
}

\section{FAITH, FOOD AND CULTURE: THE FEAST OF NOSSA SENHORA DO ROSÁRIO IN FARIA LEMOS-BENTO GONÇALVES/RS}

\section{Cleber Cristiano Prodanov}

Doutor em História Social pela Universidade de São Paulo (São Paulo/Brasil). Professor na Universidade Feevale (Novo Hamburgo/Brasil). E-mail: prodanov@ feevale.br.

\section{Hosana Maria Speranza Cimadon}

Mestra em Ciências da Saúde pela Fundação Universitária de Cardiologia (Porto Alegre/Brasil). Professora da Universidade de Caxias do Sul (Caxias do Sul/Brasil).

E-mail: hosana.cimadon@gmail.com. 


\section{RESUMO}

O objetivo desse artigo é analisar o papel representado pela comida na festa de Nossa Senhora do Rosário, no distrito de Faria Lemos, município de Bento Gonçalves/RS. Essa festa ocorre desde 1898 e está inserida em uma região marcada pela presença de imigrantes italianos. Nesse contexto, a comida sempre esteve presente de forma marcante na festa, com preparações originárias da tradição italiana e a incorporação de elementos locais. A evolução do cardápio, a mutação de seus ingredientes e do modo de preparo constituem também nosso objeto de análise. Para o entendimento dos elementos da cultura e da comida optamos por uma pesquisa de caráter inter e multidisciplinar com uso de fontes primárias e da história oral. Por fim, esse estudo também procura demonstrar como a comida exerceu um papel fundamental na constituição de uma identidade local.

Palavras-chave: Comida. Religião. Identidade. Cultura. Festa.

\section{ABSTRACT}

The purpose of this article is to analyze the role represented by the food in the feast of Nossa Senhora do Rosário in the district of Faria Lemos, Bento Gonçalves/RS. This party has been taking place since 1898 and is part of a region where Italian immigrants are significantly present. In this context, the food has always been markedly present at the parties under preparations originated from the Italian tradition and local elements incorporations. The menu changes, its ingredients variations and ways of preparation are also our objects of analysis. For the understanding of the cultural elements and food we have chosen an inter and multidisciplinary nature research by using primary sources and oral history. Finally, this study also seeks to demonstrate how the food held a key role in the establishment of a local identity.

Keywords: Food. Religion. Identity. Culture. Feast. 


\section{INTRODUÇÃO}

O presente artigo é parte de uma pesquisa maior onde investiga-se o papel da comida nas festas religiosas dos imigrantes italianos no sul do Brasil. Nesse contexto analisaremos a comida preparada e servida em uma festa religiosa e seu papel, bem como se desenvolveu a mesma ao logo dos anos.

Para essa análise, abordaremos a festa de Nossa Senhora do Rosário, padroeira do distrito de Faria Lemos, situado no município de Bento Gonçalves/RS. Essa festa ocorre anualmente no mês de outubro desde o longínquo ano de 1898. De acordo com registros paroquiais, a primeira edição da festa aconteceu no primeiro domingo de outubro de 1898 (LIVRO TOMBO I, 1916-1943).

A festa da padroeira sempre foi relevante para os sujeitos que deixaram sua terra natal na Itália, principalmente da região do Vêneto. A união das pessoas, o trabalho, a dedicação e principalmente a comida local, transformaram a festa em um evento atrativo, relacionado à identidade da comunidade local.

A preparação dos pratos servidos no almoço ao longo de todas as festas contava com a participação de homens e mulheres da localidade que, com dedicação, doação do seu tempo e produtos, faziam a união de saberes e sabores da colônia ${ }^{1}$, transformando produtos locais em refeições.

Assim, pode-se dizer que a comida foi um elemento agregador na festa de Nossa Senhora do Rosário e fator preponderante à identidade cultural dessa comunidade. Essa afirmativa vai ao encontro do que Montanari (2013) escreve sobre comida como cultura quando diz que comida é cultura quando produzida, pois o homem, ao contrário de outras espécies animais, cria a própria comida e a prepara com produtos de base da sua alimentação, transformando-a por meio do fogo e de técnicas elaboradas expressadas na cozinha e, é cultura, também porque é consumida. O homem escolhe o que deseja consumir seguindo critérios econômicos, nutricionais e simbólicos que a comida apresenta.

Para Morigi, Rocha e Semensatto (2012), as festas comunitárias são práticas culturais em que são ressignificados saberes locais que estão vinculados em muitos aspectos com elementos tradicionais. Assim, a manutenção da memória social está associada à cultura imaterial ${ }^{2}$, e nos festejos a tradição cultural possui centralidade e é exaltada desde a concepção do evento.

\footnotetext{
${ }^{1}$ A expressão saberes e sabores da colônia foi inspirada no título do livro de: MENASCHE, Renata. Saberes e Sabores da Colônia: alimentação e cultura como abordagem para o estudo rural. Porto Alegre: Editora UFRGS, 2015.

2 Entendemos cultura imaterial como uma manifestação de elementos representativos, de hábitos, de práticas e costumes.
} 
Analisar os processos culturais, em especial as peculiaridades alimentares junto à festa, é de fundamental importância para entender com profundidade o papel que a comida representou na comunidade de Faria Lemos. De acordo com Montanari (2013), a história contada e não registrada pode perder-se com o passar dos tempos ou sofrer alterações devido aos esquecimentos.

Segundo o sociólogo inglês Jack Goody (apudMONTANARI, 2013, p. 62), a cozinha escrita permite codificar, em um repertório estabelecido e reconhecido, as práticas e as técnicas elaboradas em determinada sociedade. A cozinha oral teoricamente está destinada, em longo prazo, a não deixar traços de si. Para ele, mesmo que os textos escritos nunca sejam expressão direta de uma cultura popular, eles, todavia, a representam com fidelidade muito maior do que poderíamos esperar.

Muito poucos são os estudos que falam da comida como cultura nas festas religiosas realizadas em regiões colonizadas por italianos no Estado do Rio Grande do Sul, por isso é importante pesquisar sobre o tema: saber como os pratos da culinária eram preparados nas diferentes épocas, os insumos utilizados, os utensílios, os equipamentos, os temperos, os saberes e como as pessoas se organizavam nas tarefas do início ao final da festa.

Dados de Gomes e Laroque (2010) dão conta de que os principais elementos da cultura trazidos pelos imigrantes italianos que se estabeleceram no Rio Grande Sul, a partir de 1875, são o uso de dialetos de cada região de costume e também as residências, a alimentação, a vestimenta, o divertimento, a música, o lazer e a religião. A fé e a cultura, em conjunto, constituíram uma força de coesão muito forte. Foi através da religião que os primeiros imigrantes se agregaram na identificação, principalmente do dialeto e dos sabores alimentares. Assim foram se aglomerando em comunidades formando a sua própria identidade cultural.

Apesar do significativo número de livros e artigos sobre a história da alimentação, a gastronomia, especificamente no Rio Grande do Sul, é recente e precisa ser elaborada com mais profundidade nos diversos contextos sociais, inclusive quando se trata da comida presente em festas religiosas, como é o caso da festa de Nossa Senhora do Rosário de Faria Lemos.

Esta pesquisa envolveu a utilização de fontes históricas primárias, como o livro Tombo³ paroquial e história oral, onde, por meio de 6 entrevistas com pessoas da comunidade que participaram da

\footnotetext{
${ }^{3}$ Livros Tombo: são os livros da paróquia onde foram registradas as informações referentes à comunidade local: número de habitantes, idioma e religião dos moradores, número de óbitos, acontecimentos da comunidade com as festas religiosas e as missas, dentre outros. Os registros foram feitos por cada pároco da época.
} 
organização da liturgia e do preparo da comida da festa, buscaram-se informações relevantes sobre o evento, especialmente no que diz respeito à comida.

\section{COMIDA E COMUNIDADE}

Desde a mais remota antiguidade o ato de comer e beber foi relacionado às celebrações, a ritos de passagem e a momentos especiais das sociedades. Em culturas em que a religiosidade se relacionava intimamente com a vida cotidiana, como a judaico-cristã, comemorar ou "bebemorar" eram formas extremamente prazerosas de cultuar os deuses e celebrar a vida. Também, compartilhar a comida era uma forma de solidariedade e de reafirmar vínculos (CAVACCHIOLI apud MIRANDA; CORNELLI 2007).

As festas comunitárias são práticas culturais onde são produzidos, transmitidos e usados saberes da tradição e da cultura local. Nesse sentido, a manutenção da memória social está associada à cultura imaterial. Nos festejos, a tradição cultural possui centralidade e é exaltada desde a concepção do evento, se perpetua nas práticas culturais, na reprodução das diferenças de comportamento, nas formas de conceber o mundo, nas relações de poder entre os gêneros masculino e feminino e seus espaços, manifestando-se ainda nas crenças, no modo de vida, na memória coletiva e na história social do grupo.

A festa de Nossa Senhora do Rosário teve sua origem logo após a chegada dos imigrantes italianos na região, sendo que tinham na religião um dos fatores mais importantes nas suas vidas e o catolicismo foi o principal componente da identidade coletiva desse povo (CORRÊA, 2013). A sociabilidade daqueles colonos era limitada às festas religiosas e à missa dominical (ZANINI, 2007). Essa afirmativa é confirmada pela fala de uma moradora atual da comunidade (entrevistada 3,68 anos) que atua na parte litúrgica das celebrações religiosas desde os anos 60 e que nos diz; "As festas religiosas eram o encontro de tudo no que diz respeito à parte social. As moças, por exemplo, aguardavam o caminhão para a paquera, pois nele vinham muitos rapazes para a missa de domingo e para as festas".

De acordo com Abreu e Mattos (2013), os historiadores têm atribuído inúmeros significados e interpretações às festas, tais como, locais de encontros, janelas de estudo para uma dada conjuntura, caminhos de conflito e/ou formação de identidades (étnicas, locais e nacionais).

Além disso, para Morigi, Rocha e Semensatto (2012), os rituais festivos e religiosos têm dinâmicas próprias, constituindo-se como atos coletivos "extra-ordinários", "extra-temporais" e "extra-lógicos", espaços em que se interligam elementos do comer, beber, partilhar e alegrar-se e, nesse sentido, neles se 
realizam consumação, dispêndio, sacrifício, troca-dom, reciprocidade, ou seja, o ato mesmo de produção da vida. Nessa acepção, a festa é um espaço privilegiado de circulação de alimentos, da dádiva da oferta desses a vizinhos, parentes, amigos e também à divindade.

Até o final dos anos 50 do século passado, o almoço da festa se resumia a uma sopa feita com "brodo4", pão colonial e queijo colonial ralado, tudo doado pelas famílias da comunidade, segundo os depoimentos das obreiras da época "Não tinha espaço e nem louça para fazer outras comidas e o salão paroquial era uma casa pequena, velha e de madeira (entrevistada 4, 85 anos) ".

Nos anos 1960, com a chegada de um novo pároco, que segundo a entrevistada 3, 68 anos, "tinha ideias inovadoras" e sugeriu modificações no cardápio, o mesmo que era composto apenas da sopa de pão foi modificado incluindo a sopa de capeletti, ${ }^{5}$ carne lessa ${ }^{6}$, massa (bigoli) ${ }^{7} \mathrm{com}$ molho, salada verde (alface e/ou radite), batata com maionese caseira8, galeto e churrasco. Esses pratos eram típicos dessa região colonizada por imigrantes italianos que trouxeram seu conhecimento culinário e adaptaram seus ingredientes aos pratos locais, como o churrasco.

Esse movimento de manutenção e inclusão pode ser bem observado em grupos sociais e étnicos que se deslocam, como os imigrantes europeus que saindo da Alemanha, Itália, Portugal ou outro país, tendem a preservar algumas tradições, mas também incorporam novos produtos, pratos ou elementos à sua

\footnotetext{
${ }^{4}$ Brodo: é o caldo utilizado para o preparo da sopa. Segundo a cozinheira mais antiga da festa (entrevistada 4, 85 anos) até os anos 60, esse caldo era feito com galinha caipira velha e temperos naturais, como a cebola verde e o tomilho. Depois dos anos 60 foi introduzida carne de gado e um saco com temperos (cebola verde, tomilho, louro, noz moscada). Dentro do saco também eram colocados pão e pedaços de queijo duro (curado). Nos últimos anos acrescentou-se caldo concentrado de galinha. 0 termo "brodo" ainda é utilizado por muitos na comunidade.

${ }^{5}$ Capeletti ou Agnolini: de acordo com FIGUEIREDO (2010), é um formato de massa geralmente recheada com frango (eventualmente acrescido de carne de gado), pão ralado, queijo e ovos para dar ponto. Além de temperos frescos, noz moscada e às vezes canela. Na Itália é cozido e servido com molho. No Brasil, especialmente na Serra Gaúcha, é preparado com caldo (brodo) e servido como sopa devido ao frio. No cardápio da festa de Nossa Senhora do Rosário sempre foi utilizado o termo capeletti e não agnolini.

${ }^{6}$ Carne lessa: é carne de aves e/ou gado utilizada para fazer o brodo (caldo). Cozida por muitas horas torna-se macia. Nas festas é servida juntamente com a sopa e a salada. 0 termo lesso foi utilizado no cardápio das festas e significa carne lessa.

${ }^{7}$ Bigoli: é uma massa semelhante ao espaguete, porém mais grossa. Antigamente amassava-se com as mãos e era moldada no bigolaro. Nas últimas duas décadas, tanto a massa quanto a moldagem foram feitas em máquina própria.

${ }^{8}$ Maionese caseira: de acordo com relatos da cozinheira mais antiga da festa (entrevistada 4, 85 anos), o molho de maionese era feito com gemas cozidas, gemas cruas, óleo, sal e limão. Tudo era amassado com garfo e misturado nas batatas. Era preciso várias mulheres para conseguir preparar a quantidade necessária. Nos últimos anos utilizou-se a maionese industrializada por questões de segurança, já que esta é preparada com ovos pasteurizados.
} 
culinária. Mesmo que nem sempre seja perceptivel essa alteração e que depois de algumas gerações esses elementos se dissipem ela continua presente.

Os pratos locais, ligados a produtos locais, evidentemente existem desde sempre. Sob esse ponto de vista, a comida, é, por definição, mais diretamente ligada aos recursos do lugar. Mas também, no plano mais alto, mesmo quando entra em jogo a variante decisiva do mercado, a atenção ao produto "com denominação de origem" não é novidade (MONTANARI, 2013, p. 135-136).

A ampliação do cardápio proporcionou a construção de um salão de alvenaria, pois o "lucro" da festa era todo investido na obra. "A gente tinha que ir lavando os pratos que iam voltando da mesa para repor a comida; não tinha louça que chega, tinha que fazer de 100 a 120 almoços, todo dinheiro da festa era para a construção do salão (entrevistada 4, 85 anos) ". Os homens cuidavam do churrasco e as mulheres das comidas feitas na cozinha. "O trabalho começava na terça-feira com a lavagem das cadeiras, mesas e louças pelos jovens, disse a entrevistada 5,67 anos. " "As mulheres matavam as aves que eram doadas e separavam "as mais "velhas" para o brodo da sopa e as aves mais novas eram assadas no domingo em forno de barro para serem servidas no almoço (entrevistada 4, 85 anos). " Aqui se pode observar o uso do saber, onde o alimento é transformado em comida a partir de um conhecimento prévio: aves mais velhas produzem um brodo mais saboroso e aves jovens, de carnes mais tenras, servem para serem assadas.

No sábado eram feitos os capelettis e os bigolis que, segundo a entrevistada 1, 76 anos, "tudo era feito a mão, não tinha máquinas. A base do recheio dos capelettis era carne de gado e miúdos das aves. Se usava temperos naturais como salsa, cebolinha e tomilho e o pão servia para dar liga. Também era utilizado queijo ralado".

Na Festa de Nossa Senhora do Rosário, além da religião, a comida sempre foi um fator marcante, pois foi por meio do almoço preparado e servido ao longo dos anos que ocorreram diferentes formas de comunicação e expressão entre as pessoas. Do preparo ao consumo, a proximidade das pessoas favoreceu a conversa, as risadas, a diversão e a construção de laços de amizade e trocas, enquanto saboreavam a comida. "A comida sempre foi servida em mesas com $5 \mathrm{~m}$ de comprimento, com as pessoas uma ao lado da outra (entrevistada 1, 76 anos) ".

De acordo com Santos (2011) os alimentos não são apenas alimentos e comer é um ato social, pois envolve atitudes, ligadas aos usos, costumes, protocolos, condutas e situações. 0 alimento que entra 
em nossa boca não é neutro. A historicidade da sensibilidade gastronômica explica e é explicada pelas manifestações culturais e sociais.

Em todos os níveis sociais, a participação na mesa comum é o primeiro sinal de pertencimento ao grupo, que pode ser a família, mas também uma comunidade mais ampla onde se reafirma a própria identidade coletiva. Segundo Montanari (2013, p. 157):

Comer junto é típico (ainda que não exclusivo) da espécie humana [...] não nos convidamos uns aos outros para comer e beber simplesmente, mas para comer e beber juntos [...] a comida se define como uma realidade deliciosamente cultural, não apenas em relação a própria substância nutricional.

Outro aspecto de importância singular é o que aponta Maciel (2001) que é a relação da comida com o ser social, ou seja, com quem comemos. Segundo a autora, "o comer juntos" é o momento de reforçar a coesão do grupo, pois ao partilhar a comida, partilham-se sensações, tornando-se uma experiência sensorial (MACIEL, 2001, p. 142).

Para Santos (2011), uma comunidade pode manifestar na comida emoções, sistemas de pertinências, significados, relações sociais e sua identidade coletiva e, se a comida é uma forma de comunicação, assim como a fala, ela pode contar histórias e se constituir como narrativa da memória social de uma comunidade. 0 autor continua dizendo que lendas ou crenças, festas ou jogos, costumes ou tradições, são fenômenos que não dizem nada por si mesmos, eles apenas dizem algo enquanto parte de uma cultura, a qual não pode ser entendida sem referência à realidade social de que faz parte a história da sua sociedade. Os eventos tradicionais, apesar de se repetirem ao longo do tempo e em vários lugares, não são sempre iguais.

A comida, conforme Montanari (2013) pode transmitir valores simbólicos e significados de natureza variada, como: econômicos, sociais, políticos, étnicos, estéticos, religiosos, etc. O sistema alimentar, como a língua falada, contém e transporta a cultura de quem a pratica, depositando tradições e a identidade de um grupo.

O fato de que as tradições de uma cultura possam ser identificáveis, não quer dizer que não se transformam ou que não tenham sua dinâmica, pois a cultura não é estanque.

Desde a primeira festa de Nossa Senhora do Rosário em 1898, ocorreram algumas mudanças, principalmentenos últimos anos. Alguns ingredientes foram substituídos, como a maionese industrializada 
no lugar da caseira, as aves passaram a ser compradas: para sopa aves mais "velhas" e inteiras e, para assar, coxa e sobrecoxa. 0 recheio dos capelettis não é feito com miúdos, apenas com a carne de gado moída, o pão é feito em padarias e o queijo industrializado.

Outra mudança que também pôde ser observada foi no preparo do churrasco, um prato típico do Rio Grande do Sul e que já se fez presente nas primeiras edições da festa, composto apenas de carne de gado. Ao longo dos anos foi incorporado o frango (especialmente os cortes de coxa e sobrecoxa) e a carne de porco, posteriormente a de ovelha. No final do século XIX e início do XX, as carnes eram assadas em espetos de madeira feitos com ramos de árvore. "Cada churrasqueiro tinha que conseguir e trazer para a festa no mínimo 20 espetos, eram 12 churrasqueiros. Depois começaram a usar espeto de metal (entrevistado 2, 78 anos) ".

Santos (2011) sinaliza que em um grupo social imigrante, a culinária é a última a se desnacionalizar, evidenciando um processo de resistência, onde a construção das cozinhas, a partir da premissa de que os alimentos constituem uma categoria histórica, são marcadas pelas novas condições materiais, novos utensílios, novas tecnologias, novos ingredientes, novos alimentos, novos caminhos, novas rotas de abastecimento, novos mercados, novos hábitos alimentares, novos imaginários e muita invenção e criatividade. Daí a importância das festas, que representam um meio para a manutenção da culinária.

De acordo com a entrevistada 5, 67 anos, que foi uma das cozinheiras responsáveis pelas últimas festas "foi usada maionese industrializada para evitar problemas, já que não pode usar ovo cru". Além disso, nos novos tempos as aves são compradas de frigoríficos, pois as famílias da comunidade não as criam mais, atualmente elas dedicam quase que exclusivamente seu trabalho às atividades da vitivinicultura.

Questionada sobre as doações de produtos para o preparo da comida, a entrevistada 6, 55 anos, informou que as mesmas continuam, porém nas últimas festas foram doados produtos de limpeza, farinha de trigo branca para as massas e, se as famílias quiserem fazer outros tipos de doações, também podem. "Se alguma família doa um produto que não precisa para o preparo do almoço, nós negociamos com o mercado e trocamos. Mas aqui todo mundo já sabe o que precisa para a festa". Essa fala é uma de muitas que demonstram o vínculo que existe ainda hoje entre as pessoas da comunidade e os preparativos da festa, além de tornar evidente o papel que a comida representou ao longo desses anos todos, uma vez que esta prática sempre contribuiu para o resultado positivo da festa. "As pessoas sempre doaram produtos para que o custo da festa fosse menor e tivesse mais lucro (entrevistada 1, 76 anos)". 
Foi por meio dessas doações e do trabalho em mutirão que a festa de Nossa Senhora do Rosário possibilitou ao longo dos anos um retorno financeiro e, com isso, o investimento em utensílios e equipamentos para a cozinha, resultado da venda dos ingressos para o almoço festivo.

Algumas cozinheiras (entrevistadas 5, 67 anos e 6, 55 anos) relataram que nas últimas festas não havia mais falta de louças, utensílios, equipamentos e que até festas de casamento foram realizadas nos últimos anos, aproveitando a excelente estrutura que existe graças ao sucesso e a organização da festa de Nossa Senhora do Rosário. Segundo elas, "hoje temos tudo, não falta nada, até toalhas para as festas de casamento temos. É mais fácil trabalhar".

Nesse contexto, ao longo dos anos, percebe-se que ocorreram adaptações às circunstâncias do gosto e das práticas alimentares, onde história, comida e identidade criaram e mantiveram uma articulação permanente. Existe uma dinâmica cultural que vai transformando os saberes, incorporando, descartando e fazendo seu caminho histórico e cultural.

\begin{abstract}
Ashistórias quecontamos nos lembram que todaacultura, todaatradição, todaaidentidade é um produto da história, dinâmico e instável, gerados por complexos fenômenos de troca, de cruzamento, de contaminação. Os modelos e as práticas alimentares são o ponto de encontro entre as culturas diversas, fruto da circulação de homens, mercadorias, técnicas, gostos de um lado para outro do mundo. Digamos mais: as culturas alimentares (e as culturas em geral) são mais ricas e interessantes quanto mais os encontros e as trocas tenham sido vivazes e frequentes (MONTANARI, 2013, p. 189).
\end{abstract}

Para Magalhães (2007), as práticas culinárias expressam aspectos fundamentais da vida cotidiana de uma cultura, além de costumes, valores e tradições de uma época.

Em conversa com a entrevistada 6, 55 anos, descobriu-se que ela passou a trabalhar na cozinha da paróquia quando sua sogra (entrevistada 4, 85 anos), não pôde mais trabalhar. Esse fato mostra a continuidade do trabalho comunitário e gratuito, bem como a transmissão de saberes. De acordo com seu depoimento, "as pessoas que trabalham na cozinha aprenderam com as mulheres que trabalharam antes".

Segundo Montanari (2009), a cozinha é um lugar de identidade e trocas: a cozinha contém e expressa a linguagem dos que a praticam e guarda as tradições e identidades de um grupo, sendo um extraordinário veículo de autorrepresentação e de comunicação.

É importante também ressaltar o trabalho das pessoas da comunidade para o êxito da festa. Nos depoimentos colhidos observou-se que as diferentes gerações que passaram por ela doaram seu 
tempo e seu saber de forma voluntária com o objetivo de buscar o fortalecimento local e a manutenção desse evento religioso tão marcante para a localidade. "Todas as pessoas que trabalham na festa são voluntárias, pois o dinheiro que entra é em benefício da comunidade (entrevistada 6, 55 anos) ".

Em relação aos jovens, observou-se, segundo a entrevistada 5, 67 anos, que a participação tem diminuído nos últimos anos. Segundo ela, "hoje eles têm outros atrativos, muitos estudam na cidade, tem mais condições. Antigamente a festa era o que eles tinham de lazer". Mesmo assim, muitos jovens auxiliam na festa servindo o almoço, seus pais trabalham na churrasqueira e as mães na cozinha.

Os imigrantes italianos no Rio Grande do Sul eram em sua maioria católicos praticantes e a participação nas celebrações litúrgicas, nos domingos e dias de festa, era uma obrigação moral, pois só o praticante era considerado pessoa de fé, digno de estima e aceito pelos demais (GOMES; LAROQUE, 2010). A festa de Nossa Senhora do Rosário demonstrou, ao longo dos anos, que a religião esteve fortemente ligada com a vida das pessoas da comunidade e que, com alegria, diversão e muita comida exaltaram sua padroeira mantendo viva a tradição local.

Nos últimos anos do século $X X$, muitas famílias vindas de outras localidades passaram a morar na comunidade de Faria Lemos, trazendo consigo suas crenças, sua cultura e a sua religião e a comunidade que no início da sua formação era predominantemente católica, tem observado a participação de todas essas pessoas na festa, pois a comida tem sido o principal atrativo para a maioria dos participantes segundo a entrevistada 5, 67 anos. "Antigamente as pessoas iam à festa mais pela devoção, hoje vão mais para comer".

Com base nas entrevistas feitas, observou-se que nas últimas festas houve a participação de pessoas de outras comunidades, inclusive da zona urbana, sendo que a maioria das pessoas foi para a festa apenas para o almoço, o que corrobora com as ideias de Magalhães (2007) que diz que em torno da comida ocorrem diferentes formas de articulação do social, do lúdico e do religioso, independente da religião.

Todas essas mudanças que aconteceram ao longo dos anos são importantes de serem registradas para que não se percam e, principalmente, para que as futuras gerações saibam do que aconteceu e da importância desses acontecimentos.

A esse respeito, o sociólogo inglês Jack Goody (apud MONTANARI, 2013) afirma que a construção de uma memória escrita da cozinha, torna possível o desenvolvimento cumulativo dos conhecimentos e 
se concretiza em um verdadeiro saber constituído, o que não se verifica, pelo menos em forma material e tangivel, nas sociedades de tradição oral. A cozinha escrita permite codificar, em um repertório estabelecido e reconhecido, as práticas e as técnicas elaboradas em determinada sociedade.

A cozinha oral, teoricamente, está destinada, em longo prazo, a não deixar traços de si. Para o sociólogo, mesmo que os textos escritos nunca sejam expressão direta de uma cultura popular, eles, todavia a representam com fidelidade muito maior do que poderíamos esperar.

Maciel (2005) refere que na alimentação humana, natureza e cultura se encontram, pois se comer é uma necessidade vital, o quê, quando e com quem comer são aspectos que fazem parte de um sistema que implica atribuição de significados ao ato alimentar. Se os homens comessem apenas para sobreviver poderiam fazê-lo de modo particular, mas eles criam "maneiras de viver" diferentes, o que resulta em uma grande diversidade cultural. De acordo com Maciel (2005), a cozinha de um grupo é muito mais do que um somatório de pratos considerados característicos ou emblemáticos. É um conjunto de elementos referenciados na tradição e articulados no sentido de constituí-la como algo particular, singular, reconhecível diante de outras cozinhas.

Ela não pode ser reduzida a um inventário, convertida em fórmulas ou combinações de elementos cristalizados no tempo e no espaço. Uma vez que a identidade social é entendida como um processo dinâmico relacionado a um projeto coletivo que inclui uma constante reconstrução, e não como algo dado e imutável, pode-se afirmar que essas cozinhas agem como referenciais identitários, estando sujeitas a constantes transformações.

Brillat-Savarin (1995) escreveu em seu livro A Fisiologia do Gosto que a gastronomia é um dos principais vínculos da sociedade e é ela que amplia o espírito de convivência que reúne a cada dia as diversas condições, funde-as em um único todo, anima a conversação e suaviza os ângulos da desigualdade convencional.

Os significados históricos e antropológicos da alimentação permitem captar traços da dinâmica, fazendo com que a comida seja constitutiva da identidade de um grupo, que se mantém viva nas tradições e na memória. Nesse sentido, a alimentação deve ser considerada como patrimônio histórico gustativo de uma cultura, associada ao cotidiano dos indivíduos, das pessoas e dos grupos e como espaço de vida que se destaca como categoria histórica (SANTOS, 2011). 
Por outro lado, para Geertz (2008), os sistemas culturais devem ter um grau mínimo de coerência, do contrário não os chamaríamos de sistemas e, através das observações vemos que eles têm muito mais do que isso. 0 autor cita que se deve atentar para o comportamento, e com exatidão, pois é através do fluxo de comportamento e, mais precisamente pela ação social, que as formas culturais encontram articulação.

Iniciar o estudo da Festa de Nossa Senhora do Rosário, com ênfase na comida, foi uma maneira de explorar as particularidades locais de uma pequena comunidade, Faria Lemos, permitindo o enriquecimento da análise social, tornando-a mais complexa, pois levou em conta aspectos diferentes, inesperados, multiplicados da experiência coletiva, características do estudo da micro história.

Para Barros (2007) a comunidade examinada pela micro história pode aparecer como um meio para alcançar a compreensão de aspectos específicos relativos a uma sociedade mais ampla.

\section{CONSIDERAÇÕES FINAIS}

Partindo do princípio de que este trabalho procurou principalmente refletir sobre a comida e seu papel ao longo da trajetória da festa de Nossa Senhora do Rosário, mesmo em uma abordagem mais restrita, acreditamos que foi possivel mostrar que esse evento foi crescendo e se transformando com o passar dos anos e, mesmo que a comida sofreu algumas alterações em termos de ingredientes, pratos e a introdução de equipamentos e utensílios, a união em torno do trabalho e da manutenção da festa continuou presente na comunidade, mantendo-se um forte laço entre a religiosidade, a comida e a cultura local.

Em um mundo globalizado no qual as informações e a tecnologia moderna chegam de forma muito rápida até as pessoas, é natural que a comunidade estudada também tenha se transformado, pois este é um processo inerente e faz parte da cultura. 0 que de início era braçal foi substituído por máquinas (a máquina de fazer massa), os produtos industrializados também foram incorporados, até mesmo o espeto de metal, os liquidificadores, as batedeiras, enfim, uma série de mudanças que vieram para atender o número maior de pessoas que participaram do almoço e facilitar o trabalho de homens e mulheres da comunidade.

A manutenção da festa de Nossa Senhora do Rosário é uma forma de preservar a memória desses imigrantes e sua trajetória, bem como a contribuição que deram ao povo de Faria Lemos. A comida preparada e servida na festa foi saboreada por diferentes gerações nos últimos anos mantendo, assim, a tradição local e proporcionando uma visibilidade maior da localidade. 


\section{REFERÊNCIAS}

ABREU, Martha; MATTOS, Hebe. Festas, patrimônio cultural e identidade negra, rio de janeiro, 1888 2011. Artelogie, n. 4, jan. 2013.

ALBERTI, Verena. Manual de História Oral. Rio de Janeiro: FGV, 2004.

BOSI, Ecléa. Memória e Sociedade: lembranças de velhos. São Paulo: Companhia das Letras.1999.

BRILLAT-SAVARIN, Jean Anthelme. A fisiologia do gosto. São Paulo: Companhia de Letras, 1995.

CAVACCHIOLI, Marina Regis. Comer, beber e viver. Festa e Êxtase Alimentar. In: MIRANDA, Danilo S. de; CORNELLI, Gabriele (Org.). Cultura e alimentação: Saberes Alimentares e Sabores Culturais. São Paulo: SESC, 2007.

FERREIRA, Marieta de Moraes; AMADO, Janaína (Org.). Usos \& Abusos da História Oral. 2. ed. Rio de Janeiro: Fundação Getúlio Vargas, 1998.

FIGUEIREDO, Franciele B. Referências Imateriais: o estudo do agnolini. In: ANAIS DO VI SEMINÁRIO DE PESQUISA EM TURISMO DO MERCOSUL: Saberes e fazeres no turismo: Interfaces- $6^{\circ}$ Semintur-UCS: Universidade de Caxias do Sul, 2010. Anais... Universidade de Caxias do Sul, 2010. Disponível em: <http:// www.ucs.br/ucs/tpIVSeminTur\%20/eventos/seminarios_semintur/semin_tur_6/gt13/arquivos/13/ Referencias\%20lmateriais\%200\%20estudo\%20do\%20Agnolini.pdf> Acesso em: 04 dez. 2016.

GEERTZ, Clifford. A Interpretação das Culturas. 1. ed. Rio de Janeiro LTC, 2008.

GOMES, Vanderlisa Ferreira; LAROQUE, Luís Fernando da Silva. História e cultura dos imigrantes e seus descendentes: o costume do filó em localidades do Vale do Taquari/RS. Revista Destaques Acadêmicos, Lajeado, RS, n. 2, 2010.

MACIEL, Maria Eunice. Olhares Antropológicos Sobre a Alimentação: identidade cultural e alimentação. In: CANESQUI, Ana Maria; GARCIA, Rosa Wanda Diez (Org.). Antropologia e nutrição: um diálogo possível. Rio de Janeiro: Editora FIOCRUZ, 2005.

. Cultura e alimentação ou o que tem a ver os macaquinhos de Koshima com Brillat-Savarin.

Horizontes Antropológicos, Porto Alegre, a. 7, n. 16, p. 145-156, dez. 2001. 
MAGALHÃES, Antônio Carlos de Melo. Comida, festa e religião no Brasil. In: MIRANDA, Danilo S. de; CORNELLI, Gabriele (Org.). Cultura e alimentação: saberes alimentares e sabores culturais. São Paulo: SESC, 2007.

MENASCHE, Renata. Saberes e sabores da Colônia: alimentação e cultura como abordagem para o estudo rural. Porto Alegre: Editora da UFRGS, 2015.

MONTANARI, Massimo. 0 mundo na cozinha: história, identidade e trocas. São Paulo: Estação Liberdade, 2009.

Comida como Cultura. São Paulo: Editora Senac, 2013.

MORIGI, Valdir Jose; ROCHA, Carla Pires Vieira da; SEMENSATTO, Simone. Memória, representações sociais e cultura imaterial. Morpheus, Rio de Janeiro, n. 14, p. 182 - 191, 2012.

PARÓQUIA NOSSA SENHORA DO ROSÁRIO DE FARIA LEMOS. Livro Tombo I. Bento Gonçalves, RS, 1916-1943.

SANTOS, Carlos Roberto Antunes dos. A comida como lugar de história: as dimensões do gosto.

Questões e \& Debates, Curitiba, n. 54, p. 103 - 124, jan./jun. 2011. Disponível em: <file:///C:/

Users/0060093/Downloads/25760-93881-1-PB.pdf>. Acesso em: 11 set. 2015.

THOMPSON, Paul. A Voz do Passado. História Oral. 2. ed. São Paulo: Paz e Terra, 1988.

ZANINI, Maria Catarina Chitolina. Um olhar antropológico sobre fatos e memórias da imigração italiana. MANA, Rio de Janeiro, n. 2, 2007. Disponível em: <http://www.scielo.br/pdf/mana/v13n2/09.pdf>. Acesso em: 07 out. 2015.

\section{ENTREVISTAS}

ENTREVISTA 1. CIMADON, F. R. Fiore Reginatto Cimadon: depoimento [nov.2015]. Entrevistadora: Hosana Maria Speranza Cimadon. Bento Gonçalves: 2015. Entrevista concedida ao projeto Comida como cultura: A festa de Nossa Senhora do Rosário em Faria Lemos.

ENTREVISTA 2. CIMADON, J. José Cimadon: depoimento [nov.2015]. Entrevistadora: Hosana Maria Speranza Cimadon. Bento Gonçalves: 2015. Entrevista concedida ao projeto Comida como cultura: A festa de Nossa Senhora do Rosário em Faria Lemos. 
ENTREVISTA3. POLONI, M.H.T. Maria Helena Tesser Poloni: depoimento [nov.2015]. Entrevistadora: Hosana Maria Speranza Cimadon. Bento Gonçalves: 2015. Entrevista concedida ao projeto Comida como cultura: A festa de Nossa Senhora do Rosário em Faria Lemos.

ENTREVISTA 4. BUFFON, A. Amábile Buffon: depoimento [nov.2015]. Entrevistadora: Hosana Maria Speranza Cimadon. Bento Gonçalves: 2015. Entrevista concedida ao projeto Comida como cultura: A festa de Nossa Senhora do Rosário em Faria Lemos.

ENTREVISTA 5. CORTI, I. Ivanir Corti: depoimento [nov.2015]. Entrevistadora: Hosana Maria Speranza Cimadon. Bento Gonçalves: 2015. Entrevista concedida ao projeto Comida como cultura: A festa de Nossa Senhora do Rosário em Faria Lemos.

ENTREVISTA 6. BUFFON, C.S. Carmem Sikorski: depoimento [nov.2015]. Entrevistadora: Hosana Maria Speranza Cimadon. Bento Gonçalves: 2015. Entrevista concedida ao projeto Comida como cultura: A festa de Nossa Senhora do Rosário em Faria Lemos. 